\title{
XXXVII. On the molecular constitution of isomeric solutions \&C
}

\author{
Dr. G. Gore F.R.S.
}

To cite this article: Dr. G. Gore F.R.S. (1889) XXXVII. On the molecular constitution of isomeric solutions \&C, Philosophical Magazine Series 5, 28:173, 289-303, DOI: 10.1080/14786448908621357

To link to this article: http://dx.doi.org/10.1080/14786448908621357

曲 Published online: 08 May 2009.

Submit your article to this journal $[\pi$

Џ Article views: 2

Q View related articles $₫$ 
$\lambda^{-4}, \sigma_{5}, \sigma_{10}, \sigma_{20}, \sigma_{40}$ is given by the theory, but to find the position of these points on the curves we require to know the value of $k$.

Since the triangle in my diagram is equilateral, the colour represented by any point $P$ within the triangle can be experimentally obtained in the following way:-Let a prismatic spectrum fall on a diaphragm with three adjustable slits, whose centres are at wave-lengths $63 \ddot{1}, 529$, and 457 . Make the breadths of the slits proportional to the perpendiculars drawn from $\mathrm{P}$ to the sides of the triangle. Then the three spectral rays, when compounded by a lens, will produce the colour P. The dispersion of Maxwell's spectrum is defined by the wave-lengths I have given of the sixteen equidistant points in his spectrum. In consequence, however, of individual variations in the colour sensations great accuracy would be thrown away.

Hotel Buol, Davos, July 10th.

XXXVII. On the Molecular Constitution of Isomeric Solutions \&.c. By Dr. G. Gore, F.R.S.*

TN the present research, the "voltaic balance" has been 1 applied to the detection of differences of chemical constitution of a pair of isomeric solutions; and to detect molecular and chemical changes in them, caused by heat, light, lapse of time, order of mixture, degree of dilution of ingredients, \&c.

According to the results of J. Thomsen's thermochemical investigations, as described by $\mathrm{P}$. Muir ('Principles of Chemistry,' 1884, pp. 434,437), "when nitric acid and sodium sulphate react in equivalent quantities in a dilute aqueous solution, heat is absorbed; but when sulphuric acid and sodium nitrate react under similar conditions, heat is evolved. But the final distribution of the base between the two acids will be the same in both cases, and, moreover, this distribution will be the same when equivalent quantities of the two acids (sulphuric and nitric) and the base (soda) mutually react." "When soda, nitric acid, and sulphuric acid mutually react in equivalent quantities in a dilute aqueous solution, two thirds of the soda combines with the nitric acid, and one third with the sulphuric acid." "The final division of the base between the two acids is the same whether the soda were originally present as sulphate or nitrate." (See also "Theories

* Communicated by the Author. 
of Chemistry,' by L. Meyer, translated by Bedson and Williams, 1888, pp. 470, 485.)

Experiment 1.-I have examined this instance by means of the "voltaic-balance" method with zine and platinum couples (see Roy. Soc. Proc. vol. xlv. pp. 265, 268), and have obtained the following results. Distilled water was used in making all the solutions.

\section{TABLE I. Voltaic} energy.

“A." $\mathrm{Na}_{2} \mathrm{SO}_{4}+2 \mathrm{HNO}_{3}$ gare between 73,313 and 81,579 at $18^{\circ} \mathrm{O}$. Average 77,446

“B." $2 \mathrm{NaNO}_{3}+\mathrm{H}_{2} \mathrm{SO}_{4}$ " $\quad 31,000,34,444 \quad$ " $\quad 32,722$

The solutions of each ingredient of these two mixtures were considerably diluted previous to mixing.

The numbers obtained with the mixture "A" are much more variable than those obtained with the one " $\mathrm{B}$," and it will facilitate the clear understanding of the subsequent parts of this research if I here state that the mixture " $A$ " is an unstable one, and liable to change in molecular constitution and amount of energy both during its formation and afterwards.

It is worthy of notice that notwithstanding the average voltaic energy of sulphuric acid in water is about 3.9 millions, and that of nitric acid in water is only about $3 \cdot 2$ millions (see Table II.), the mixture " $\mathrm{A}$ " containing the latter acid has about $2 \cdot 3$ times the amount of such energy of the one " $B$ " containing sulphuric acid: this is probably explained by the changes of energy which occur during mixing.

The amounts of energy show that the distribution of acids and base in the two isomeric liquids " $A$ " and " $B$ " were very different. It is evident that if one of the mixtures consists of "two thirds of the soda combined with the nitric acid, and one third with the sulphuric acid," the other liquid must have a very different molecular arrangement; and that " the final division of the base between the two acids" is not always "the same whether the soda were originally present as sulphate or nitrate." The amounts of voltaic energy, however, appear consistent with the statement that "when nitric acid and sodium sulphate react in equivalent quantities in aqueous solution, heat is absorbed; but when sulphuric acid and sodium nitrate react, under similar circumstances, heat is evolved." The mode of preparing each liquid will be described.

In each of these two solutions the following compounds may possibly be present :- $-\mathrm{H}_{2} \mathrm{SO}_{4}-\mathrm{HNO}_{3}-\mathrm{Na}_{2} \mathrm{SO}_{4}-\mathrm{NaNO}_{3}$ $-2 \mathrm{HNO}_{3}, \mathrm{H}_{2} \mathrm{SO}_{4}-\mathrm{Na}_{2} \mathrm{SO}_{4}, \mathrm{H}_{2} \mathrm{SO}_{4}-2 \mathrm{NaNO}_{3}, \mathrm{H}_{2} \mathrm{SO}_{4}-$ 
$\mathrm{Na}_{2} \mathrm{SO}_{4}, 2 \mathrm{HNO}_{3}-\mathrm{NaNO}_{3}, \mathrm{HNO}_{3}$ - and $2 \mathrm{NaNO}_{3}, \mathrm{Na}_{2} \mathrm{SO}_{4}$; besides the more complex aggregates and the total aggregate formed by the feebler chemical union of these compounds with each other (see Table IX.; also " A Method of Detecting dissolved Chemical Compounds and their Combining Proportions," Roy. Soc. Proc. vol. xlv. p. 265). The following are the relative amounts of voltaic energy of some of these substances :-

TABLe II.

Voltaic energy.

$\mathrm{H}_{2} \mathrm{SO}_{4}$ Between $3,690,476$ and 4,11

$4,111,466$ at $19^{\circ}$

C. Áverage 3,900,941

$\mathrm{HNO}_{3}$ $3,039,215$ $3,369,565$ $3,204,295$ 1,914

2,126

2,020

$\mathrm{NanO}_{3}$ 155

177

163

NaHO $(80.04+19.96$

per cent. $\left.\left.\mathrm{Na}_{2} \mathrm{CO}_{3}\right).\right\}-254,93$

$-287,037$

$-270,985$

Speaking of thermochemical measurement in this case, L. Meyer states “according to J. Thomsen's experiments, although the action of one acid upon the other, and the action of the salts on each other, do not produce any effect capable of measurement, still each acid produces a greater or less thermic effect with its own salt." And in the case of decomposition of a salt by an acid, he says "the extent of the decomposition can be determined from the value of the thermic effect." "But for this determination it is necessary to make an extensive series of experiments, showing the thermochemical effect of each pair of the substances in question. The action of each acid on the base must be separately determined, then the action of each acid on its own salt, and also on the salt of the other acid, and finally the mutual action of the two acids." "The greatest possible care has to be exercised in each individual determination, in order that the result may be trustworthy; if due caution is not observed utterly false results are easily obtained." "Secondary thermic results are also produced by the mutual action of the other bodies." ('Modern Theories of Chemistry,' pp. 466-468.) According to J. Thomsen, the value of the thermal change attending the reaction of dilute sulphuric upon dilute nitric acid "is so small that it cannot be accurately determined" ('Principles of Chemistry,' p. 435).

If, however, we employ the "voltaic-balance" method instead of the thermochemical one, not only the chemical union of each of the acids with each of the salts, and with one another, and the individual salts with each other, is clearly shown by a depression of energy, but even that of $\mathrm{Na}_{2} \mathrm{SO}_{4}$, $2 \mathrm{HNO}_{3}$, with $2 \mathrm{NaNO}_{3}, \mathrm{H}_{2} \mathrm{SO}_{4}$, and of still more complex 
aggregates with each other are indicated. The numerical results contained in the following Tables support this statement. Each definite compound formed is the one having the smallest amount of voltaic energy, and its formula is indicated by a $\operatorname{star}(*)$.

The chemical union indicated by the minimum amount of voltaic energy in Tables III. to IX. is a distinct phenomenon from the chemical and thermal changes which occur during mixing the constituent solutions of each pair of substances.

$$
\text { TABLE III.- } \mathrm{HNO}_{3}+\mathrm{H}_{2} \mathrm{SO}_{4} \text {. }
$$

Voltalc energy. $3 \mathrm{HNO}_{3}+2 \mathrm{H}_{2} \mathrm{SO}_{4}$. Between $3,604,651$ and $3,900,000$ at $11^{\circ} \mathrm{O}$. Average 3,752,325.

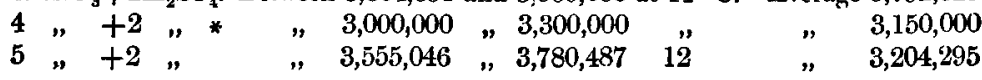

$$
\text { TABLE IV. }-\mathrm{Na}_{2} \mathrm{SO}_{4}+\mathrm{HNO}_{3} \text {. }
$$

$2 \mathrm{Na}_{2} \mathrm{SO}_{4}+5 \mathrm{HNO}_{3}$. Between 81,579 and 91,176 at $18^{\circ} \mathrm{C}$. Average 86,377 2 " +4 " * " 73,313 " 81,579 " $\quad$ " 77,446

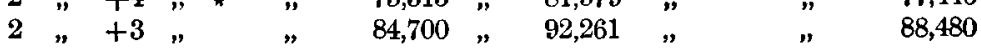

TABLE V.- $\mathrm{NaNO}_{3}+\mathrm{H}_{2} \mathrm{SO}_{4}$.

$3 \mathrm{NaNO}_{3}+2 \mathrm{H}_{2} \mathrm{SO}_{4}$. Between 33,695 and 37,440 at $18^{\circ} \mathrm{O}$. Arerage 35,564 4 " +2 "* " $\quad 31,000$ " 34,444 " $\quad$ " $\quad 32,722$

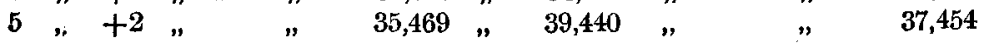

TABLE VI.-- $\mathrm{Na}_{2} \mathrm{SO}_{4}+\mathrm{H}_{2} \mathrm{SO}_{4}$.

$4 \mathrm{Na}_{2} \mathrm{SO}_{4}+5 \mathrm{H}_{2} \mathrm{SO}_{4}$. Between 31,900 and 35,477 at $12^{\circ} \mathrm{O}$. Average 33,689

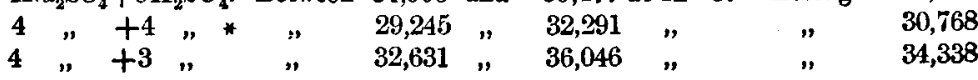

\section{TABLE VII.-- $\mathrm{NaNO}_{3}+\mathrm{HNO}_{3}$.}

$4 \mathrm{NaNO}_{3}+5 \mathrm{HNO}_{3}$. Between 24,603 and 27,200 at $12^{\circ} \mathrm{C}$. Average 25,901 $4 "+4 "$ * " $22,142,24,603$ " $, \quad 23,372$ $4 "$ "

TABLE VIII. $-\mathrm{NaNO}_{3}+\mathrm{Na}_{2} \mathrm{SO}_{4}$.

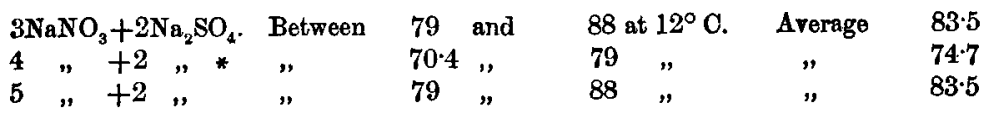

TABLE IX. $-\mathrm{Na}_{2} \mathrm{SO}_{4}, 2 \mathrm{HNO}_{3}+2 \mathrm{NaNO}_{3}, \mathrm{H}_{2} \mathrm{SO}_{4}$.

$3\left(\mathrm{Na}_{2} \mathrm{SO}_{4}, 2 \mathrm{HNO}_{3}\right)+4\left(2 \mathrm{NaNO}_{3}, \mathrm{H}_{2} \mathrm{SO}_{4}\right)$. Between 2,583 and 2,870 at $13^{\circ} \mathrm{C}$. Average 2,726

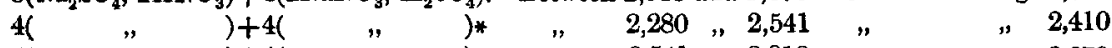

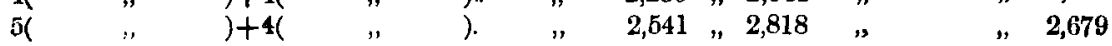


It has already been shown by the voltaic-balance method, that the action of chemical affinity between substances in aqueous solution is not limited to small groups of a few dissimilar kinds of molecules, such as those represented in Tables III. to VIII., but extends to large aggregates composed of a variety of molecules, the aggregates being apparently without limit of magnitude or variety, but subject to the law of chemical equivalence. The results given in Table IX. further support this statement. The complex structure in such cases is usually built up by making each addition chemically equivalent to the whole of the previously existing compound (see "A Method of Detecting dissolved Chemical Compounds and their Combining Proportions," Roy. Soc. Proc. vol. xlv. p. 265; also "The Loss of Voltaic Energy of Electrolytes during Chemical Union," Proc. Birm. Phil. Soc. vol. vi. part 2).

\section{Loss of Voltaic Energy during Mixing.}

In order to arrive at the loss of voltaic energy which took place during the mixing of the two constituents in each of the above cases, the average energy of each constituent was multiplied by its chemical equivalent, and the two amounts added together to obtain the total amount of energy of the constituents. The average energy of the compound was then multiplied by its molecular weight, to arrive at its total voltaic energy, and the product subtracted from the total voltaic energy of its constituents. The following are the results:--

\begin{tabular}{|c|c|c|}
\hline \multicolumn{3}{|c|}{ Table $\mathrm{X}$. } \\
\hline & Total loss. & Per cent. \\
\hline $2 \mathrm{HNO}_{3}+\mathrm{H}_{2} \mathrm{SO}_{4}$ & $80,433,388$ & $=10 \cdot 23$ \\
\hline $\mathrm{NaNO}_{3}+\mathrm{Na}_{2} \mathrm{SO}_{4} \ldots \ldots \ldots \ldots \ldots \ldots \ldots$ & 291,244 & $91 \cdot 49$ \\
\hline $\mathrm{Na}_{2} \mathrm{SO}_{4}+2 \mathrm{HNO}_{3}$ (Mixture "A"). & $383,262,482$ & 94.86 \\
\hline $2 \mathrm{~N}_{8} \mathrm{NO}_{3}, \mathrm{H}_{2} \mathrm{SO}_{4}+\mathrm{Na}_{2} \mathrm{SO}_{4}, 2 \mathrm{HNO}$ & $28,233,264$ & $95 \cdot 62$ \\
\hline $2 \mathrm{NaNO}_{3}+\mathrm{H}_{2} \mathrm{SO}_{4}($ Mixture "B")... & $373,550,432$ & $=97 \cdot 70$ \\
\hline $\mathrm{Na}_{2} \mathrm{SO}_{4}+\mathrm{H}_{2} \mathrm{SO}_{4} \ldots \ldots \ldots \ldots \ldots \ldots$ & $375,154,338$ & $=97.81$ \\
\hline $\mathrm{NaNO}_{3}+\mathrm{HNO}_{3}$ & $198,425,384$ & $=98.49$ \\
\hline
\end{tabular}

In each of these instances the loss of voltaic energy appears to be due to chemical union of the two dissolved substances. 


\section{Influence of Proportion of Ingredients upon the Amount of Energy.}

With the object of obtaining graphic representations of the influence of proportion of ingredients, the following series of measurements were made. With each mixture, 1 part by weight of each ingredient was diluted with not less than 1550 parts of water previous to mixing. The proportions of the substances employed are stated in the form of molecular weights. Only the "average" amounts of voltaic energy are given.

\section{TABle XI.}

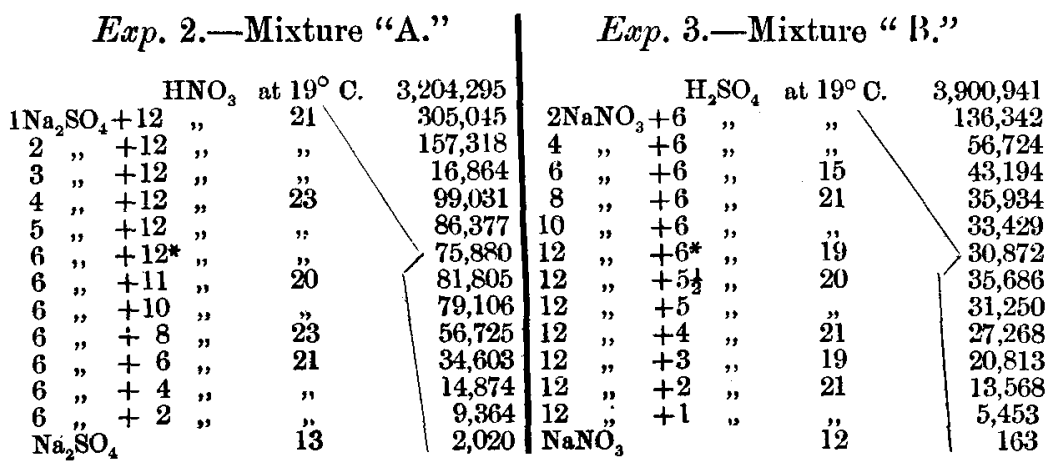

Each of these two series shows the depression of energy at the combining proportion, attending complete chemical union of the two substances. The excess of either ingredient appears to exist largely as uncombined mixture. The two chief causes which appear to determine the magnitudes of voltaic energy are, strength of chemical union of the dissolved substances with zinc, and dilution of the definite compound by the substance in excess; at the combining proportion the latter influence does not exist because there is no substance in excess. In the upper part of each series these two causes cooperate, whilst in the lower part they counteract each other: in the upper part, the stronger substance being in excess, enlarges the magnitudes ; in the lower part the weaker one is in excess, and diminishes them. The influence of dilution appears to preponderate over that of chemical union generally in each series. Variation of amount of excess of acid has in each series a much greater effect than variation of excess of salt. The following are the curves representing the above numbers :- 


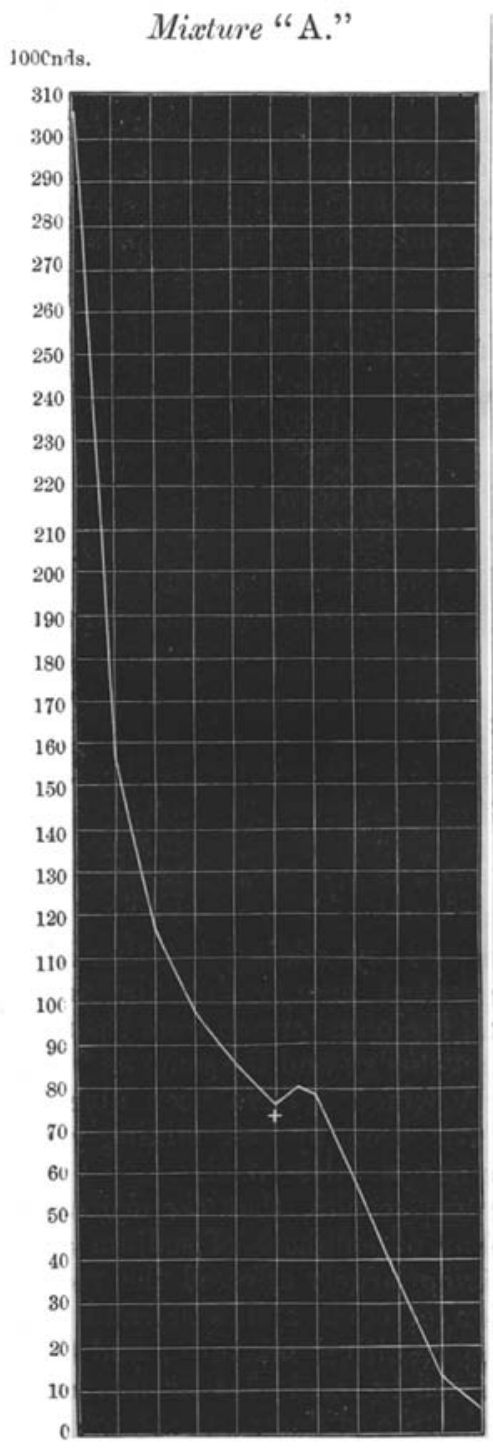

Mixture "B."

1000nds.

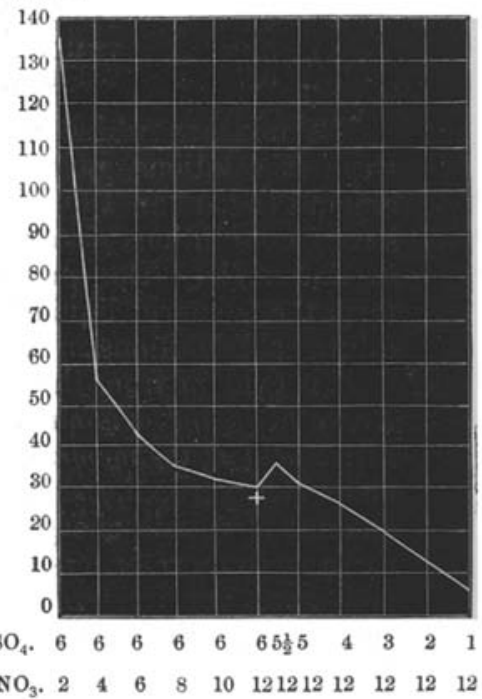

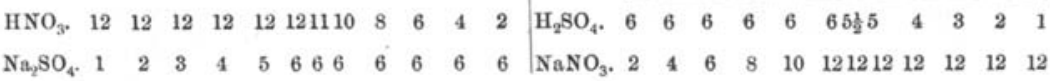


Influence of Degree of Aqueous Dilution upon the Molecular Constitution \& $c$.

Mixture "A."

Experiment 4.-Six solutions were made, each containing 1 molecular weight proportion of anhydrous sodium sulphate; and six others, each containing 2 of nitric acid. These were first diluted to different degrees, and then mixed to form six liquids of the following degrees of strength :-

$$
\text { Table XII.- } \mathrm{Na}_{2} \mathrm{SO}_{4}+2 \mathrm{HNO}_{3} \text {. }
$$

No. 1 contained 1 grain of the mixture in

$\begin{array}{lll} & 2 & \\ " & 3 & " \\ " & 4 & " \\ " & 5 & 4 \\ \text { " } & 6 & \end{array}$

10.34 grains of water.

$\begin{array}{rl}15 \cdot 50 & \text { " } \\ 155 \cdot 00 & \text { "' } \\ 310 \cdot 00 & " \\ 1,55000 & " \\ 15,500 \cdot 00 & \text { " }\end{array}$

Each of these solutions had to be further diluted previous to measuring their energy. The amounts of their voltaic energy were as follows :-

\section{Table XIII.}

No. 1. Between 30,511 and 33,917 at $12^{\circ} \mathrm{C}$. Average 32,214 .

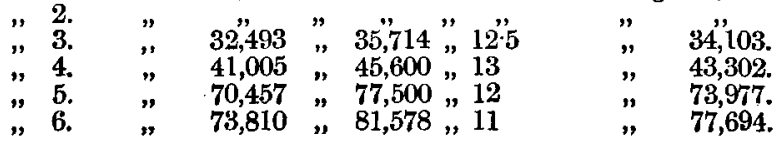

The mixture which was formed by adding together the weakest solutions gave the greatest energy and the same amount as "A" in Table I.; and the ones formed from the two strongest solutions gave the least energy and the same as "B" in that table. The only way in which I have been able to form the isomeric liquid " $A$ " has been by first mixing very dilute cold solutions in the manner just described.

It is evident from the numerical results, that the degree of strength of the original solutions of sulphate of sodium and nitric acid at the moment of mixing largely affected the molecular structure, the distribution of acids and base, and the amount of voltaic energy of the resulting mixture; and that these were more or less determined or fixed at that moment, and were not rendered alike in the different cases by the subsequent dilution necessary for the voltaic measurement. Similar results occurred with a mixture of potassic iodide and chlorine (Roy. Soc. Proc. vol. xlv. p. 440). Probably the smaller amounts of voltaic energy of the liquids made from the more concentrated original solutions were due to more 
energetic chemical action occurring at the moments of mixing of those solutions than during the mixing of the weaker ones.

\section{Mixture "B."}

Experiment 5.-Four solutions, of different degrees of strength, were also made of the isomeric mixture of 2 molecular weight proportions of sodium nitrate and 1 of sulphuric acid, exactly in the same manner as those of "A."

$$
\text { TABLE XIV.- } 2 \mathrm{NaNO}_{3}+\mathrm{H}_{2} \mathrm{SO}_{4} \text {. }
$$

No. 1 contained 1 grain of the mixture in $15 \cdot 5$ grains of water.

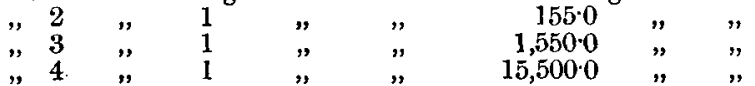

The amounts of voltaic energy given by these, after suitable dilution, were :-

\section{TABLE XV.}

No. 1. Between 30,511 and 33,917 at $15^{\circ} \mathrm{C}$. Average 32,214 .

"3. " $31,000,34,444,18$ " 182,722 .

" 4 . " $30,511,33,917 " 12.5 \quad$ " 32,214 .

That of No. 2 was not measured. The results show that the mixture of sodium nitrate and sulphuric acid was much more stable than that of sodium sulphate and nitric acid; and that variation of degree of dilution did not change the amount of its voltaic energy, and probably also not the distribution of acids and base in it.

According to the statements, that "two thirds of the soda combines with the nitric acid and one third with the sulphuric acid," and that "the final division of the base between the two acids is the same whether the soda were originally present as sulphate or nitrate," considerable chemical change must have occurred during the mixing of the ingredients of " $B$ " (as well as during that of "A"). And as the amount of voltaic energy of completely decomposed " $A$ " is the same as that obtained at the outset with " $B$ " (see Tables I. and XV.), the latter mixture attains completely its final state during the process of mixing. The thermal phenomena also support this conclusion.

In J. Thomsen's experiments with each of the mixtures " $A$ " and " $B$," " the quantity of water serving as solvent varied but slightly, so that the results of the experiments only hold good for dilute solutions" ('Theories of Chemistry,'p. 467).

\section{Influence of Order of Mixing.}

Experiment 6.-In each of the previous experiments a solution of the sult of sodium was first taken, and then one of the 
proper acid added to it; but in the present case the two dilute acids were first mixed and then a dilute solution of caustic soda added to the mixture.

Three solutions were made, of different degrees of dilution, of a mixture of 1 equivalent each of the two acids ; and three others, of similar degrees of dilution, of 1 equivalent of caustic soda ; the solutions of acid and alkali of corresponding degrees of dilution were then mixed together.

TABLE XVI.

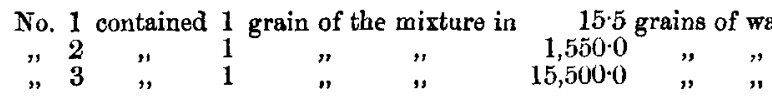

Their amounts of voltaic energy were then, after suitable dilution, measured.

\section{TABLE XVII.}

No. 1 gave between 30,511 and 33,917 at $15^{\circ} \mathrm{C}$. Arerage 32,214.

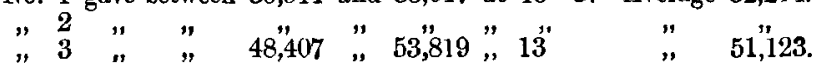

From the results of exps. 4, 5, and 6, it appears:-(1) that, with sufficiently dilute solutions of the acid and alkali, if the sulphuric acid was first added to the soda and the nitric acid then added to the sulphate of sodium, the voltaic energy of the mixture was about 73,977 ; (2) that with either concentrated or dilute solutions, if the nitric acid was first added to the soda and then the sulphuric acid to the nitrate of sodium, the energy was $=32,722$; and (3) that with all except very weak solutions, if the two diluted acids were first mixed together and then the soda added to the acid mixture, the energy was also 32,722 ; whilst with very weak ones it was $=51,123$. The order of addition of the liquids to each other therefore affects the amount of voltaic energy, the nolecular constitution of the liquid, and probably also the distribution of acids and base in it.

\section{Influence of Time.}

Experiment 7.-A solution of the mixture of sodium sulphate and nitric acid was prepared from diluted ingredients. It contained 1 grain of the mixture in 1550 grains of water, and its average voltaic energy was $=77,694$; but after standing in a dark place during 72 hours at about $11^{\circ} \mathrm{C}$. its energy was

Between 63,786 and 71,101 at $11^{\circ} \mathrm{C}$. Average 67,443.

After standing an additional 48 hours its energy was

Between 57,407 and 63,786 at $12^{\circ} \mathrm{C}$. Average 60,596 . 
The mixture " $A$ " therefore slowly altered in chemical constitution at ordinary temperatures towards that of "B." The one " $B$ " did not change under these conditions.

\section{Influence of Heat.}

\section{Mixture "A."}

Experiment 8.-Dilute solutions of sodium sulphate and nitric acid were mixed, and the mixture, containing 1 grain of substance in 1550 grains of water, and giving, after the necessary further dilution, the usual average amount of voltaic energy, viz. about 77,000, was heated during two minutes to $100^{\circ} \mathrm{C}$. in a closely stoppered glass flask, then cooled, agitated, and its amount of energy measured ; it was

Between 30,511 and 33,917 at $15^{\circ} \mathrm{C}$. Average 32,214 .

The mixture was therefore an unstable one, and its voltaic energy was rapidly and largely reduced by rise of temperature.

Experiment 9.-The solution of the same mixture, containing 1 grain of substance in 15.5 grains of water, the energy of which had already been reduced to 32,214 by insufficient dilution during its preparation (Exp. 4), was heated exactly the same as in Exp. 8 ; it then gave

Between 30,511 and 33,917 at $15^{\circ} \mathrm{C}$. Average 32,214.

Its voltaic energy therefore was unaffected.

Experiment 10.-In order to diminish the amount of chemical change which took place during the mixing of the ingredients of "A," very dilute solutions of them were taken and cooled to $3^{\circ} \mathrm{C}$. immediately before mixing. The mixture contained 1 grain of substance in 15,500 grains of water. Its amount of voltaic energy was

Between 91,176 and 100,650 at $11^{\circ} \mathrm{C}$. Average 95,913.

The lower temperature therefore diminished the amount of chemical change which occurred during the mixing (compare Exp. 4). This shows that under the ordinary conditions of temperature, when making the mixture "A" some decomposition occurred.

Experiment 11.-A precisely similar experiment was made with less diluted ingredients, forming a mixture of 1 grain of substance in 155 grains of water. Its amount of energy was

Between 30,511 and 33,917 at $11^{\circ} \mathrm{C}$. Average 32,214.

The influence of the lower temperature therefore in this case was insufficient to neutralize that of stronger solution, 
and did not prevent the maximum amount of chemical change taking place.

Lixperiment 12.-A mixture, each constituent solution of which contained 1 grain of the substance in 1550 grains of water was beated to $50^{\circ} \mathrm{C}$. during two minutes, the liquid cooled, and its energy measured; it was

Between 33,917 and 37,804 at $12^{\circ} \mathrm{C}$. Average 35,860 .

The temperature therefore was hardly sufficiently high to entirely change the mixture into the fixed product during the given period of time.

The circumstance that, by using either stronger solutions, or heated ones, of the constituents of the mixture "A," the latter yields the same amount of voltaic energy as that given by the final product of the mixture "B," agrees with the conclusion arrived at from thermochemical data that "the final division of the base between the two acids is the same whether the soda were originally present as sulphate or nitrate."

\section{Mixture "B."}

Experiment 13.- -The solutions of sodium nitrate and sulphuric acid, of the degrees of strength of Nos. 1 and 3 (Exp. 5), were mixed, the mixt'res heated to about $100^{\circ} \mathrm{C}$. during two minutes, cooled, agitated, and their amounts of energy measured. Each gave the same, viz.

Between 30,511 and 33,917 at $14^{\circ} \mathrm{C}$. Average 32,214.

The mixture " $B$ " therefore was evidently completely formed and fixed in chemical constitution at the moment of mixing, and whether the solutions of it were more or less dilute, rise of temperature did not alter their amounts of voltaic energy or their molecular constitution (see Table XV.).

Experiment 14.-In this experiment, the two dilated acids were first mixed, and heated to nearly $100^{\circ} \mathrm{C}$; a dilute solution of caustic soda, equivalent in amount to one of the acids, and equally heated, was then added to them, and the liquid cooled and agitated; it contained 1 grain of the substances in 1550 grains of water previous to dilution for measurement of its energy. The latter then was

Between 30,511 and 33,917 at $14^{\circ} \mathrm{C}$. Average 32,214.

Experiment 15.-The diluted constituent solutions of sodium nitrate and sulphuric acid in the proportion of 1 grain of substance in 15,500 grains of water were also chilled to $3^{\circ} \mathrm{C}$. and mixed. The energy was then measured, it gave

Between 31,632 and 35,227 at $10^{\circ} \mathrm{C}$. Average 33,429 . 
The difference between the numbers obtained in this case and in Exps. 5, 13, and 14 is not sufficient to prove that the cooling had any real effect upon the amount of energy.

\section{Influence of Light.}

Experiment 16.-A solution of the mixture of sodium sulphate and nitric acid was prepared from diluted ingredients which, when added together, produced a liquid containing 1 grain of the mixture in 1550 grains of water. Its voltaic energy was

Between 73,810 and 81,578 at $18^{\circ} \mathrm{C}$. Average 77,694 .

After standing the liquid in the dark during five days, its voltaic energy was

Between 57,407 and 63,786 at $12^{\circ} \mathrm{C}$. Average 60,596 (see also "Influence of Time").

A second portion of the same prepared solution was exposed in a colourless glass bottle to diffused daylight during the same period. Its voltaic energy then was

Between 58,270 and 64,583 at $12^{\circ} \mathrm{C}$. Average 61,426 .

A third portion, the energy of which at the outset was

Between 69,160 and 76,001 at $25^{\circ} \mathrm{C}$. Average 72,598, was exposed in a similar bottle to direct sunlight during five days; its energy was then reduced to

Betw'een 43,055 and 46,407 at $20^{\circ} \mathrm{O}$. Average 44,721.

In these experiments daylight had much less effect than sunlight, probably in consequence of the higher temperature in the latter case.

\section{Influence of Magneto-Electric Induction.}

Experiment 17.-A portion of the original solution "A" possessing an average voltaic energy $=75,860$ at $23^{\circ} \cdot 5 \mathrm{C}$. was placed in an annular glass vessel surrounding a voltaic coil, and a strong and rapidly intermittent current from two large Grove's elements passed through the coil during one hour, and the voltaic energy again measured; it was

Between 57,407 and 63,786 at $26^{\circ} \mathrm{C}$. Average 60,596.

To ascertain whether the change was due to rise of temperature from the heat of the coil, a similar portion of the original liquid was kept during one hour at the same average temperature; its average voltaic energy had then been similarly reduced to 60,596 . Magneto-electric induction therefore had no manifest effect.

Phil. Mag. S. 5. Vol. 28. No. 173. Oct. 1889. 


\section{Behaviour of a Solution of Sodium Sulphate.}

Experiment 18.-Dry crystals of the hydrated salt were dissolved in cold water, and the voltaic energy of the solution measured ; it was

Between 1,414 and 2,126 at $9^{\circ} \mathrm{C}$. Average 2019 (see also Table II.).

The solution was now heated to about $100^{\circ} \mathrm{C}$. in a closed glass flask during two minutes and cooled; its amount of energy now was

Between 1,839 and 2,039 at $9^{\circ} \mathrm{C}$. Average 1939.

And after boiling the solution to dryness and redissolving the salt, the average amount of energy at $9^{\circ} \mathrm{C}$. was still $=1,939$.

\section{General Conclusions and Remarks.}

It is evident from the results obtained that the chemical and molecular constitution of the liquid "A," and the distribution of acids and base in it, are affected by several circumstances : 1st By the degree of dilution of the ingredients at the moment of mixing. 2nd. The temperature of the ingredients at that moment, or to which the mixture has afterwards been subjected. 3rd. The order in which the ingredients have been added to each other. 4th. The amount of light to which the liquid has been exposed. And, 5th, the period of time which has elapsed since it was made. In addition to this, the liquid "A," even under the circumstances most unfavourable to chemical change, suffers a great and variable amount of such change during the mixing of its ingredients.

With regard to the mixture " $B$," it is well-known that it suffers chemical change, attended by liberation of nitric acid, during the mixing of its constituents. Thermochemical researches have disclosed that it forms a compound, in which one third of the soda is united to the sulphuric and two thirds to the nitric acid, leaving two thirds of the former acid and one third of the latter in a comparatively free state. The present research proves that its ingredients, at the moment of mixing, at once form a comparatively fixed substance or mixture, unalterable by various circumstances which greatly affect the mixture "A;" it also shows that the expelled portion of nitric acid probably unites chemically with an equivalent portion or one half of the free sulphuric acid; and it further proves that under certain circumstances the 
mixture "A" is changed into a fixed product, having the same amount of voltaic energy as that produced by the ingredients of " B."

With regard to the statement that " the final division of the base between the two acids is the same, whether the soda were originally present as sulphate or nitrate," the present research indicates that this is only true, provided the mixture of sulphate of sodium and nitric acid has been subjected to such conditions or influences, either during or after its preparation, as decompose and convert it into the same product as that of a mixture of nitrate of sodium and sulphuric acid.

Whilst there is greater voltaic energy in the mixture "A," there is more molecular momentum in the one "B;" and whilst the chemical change in "A" may be retarded by low temperature or dilution, it cannot be much prevented in " $\mathrm{B}$ " by either of these causes or by both combined. In "A" the chemical change which occurs during mixing only proceeds to a certain stage, if suitable precautions are taken ; in " $\mathrm{B}$ " it proceeds its entire course, and apparently with greater velocity.

The fact that by using weaker and colder solutions of the separate ingredients of the mixture "A," a larger amount of voltaic energy in the product is obtained, proves that the amount of chemical change which occurs during mixing is a variable quantity, and suggests that it may bo still further reduced. The larger the amount of voltaic energy of the freshly-made mixture, the smaller is the amount of chemical change which has occurred during the mixing. As the freshly-made mixture gradually loses voltaic energy at $20^{\circ} \mathrm{C}$., the nitric acid gradually expels sulphuric, the proportion of nitrate of sodium increases, and that of sulphate decreases.

Loss of voltaic energy does not always coincide with loss of thermal energy ; for instance, in making the mixture " $A$ " heat is absorbed, but in making the one " $\mathrm{B}$ " heat is evolved; whilst in both cases the amount of voltaic energy is diminished. In making " $A$ " the loss of energy is 94.86 per cent., and in making "B" $97 \cdot 70$ per cent. (see Table $X$.).

The "voltaic balance" is a very convenient instrument for detecting and measuring molecular changes in dissolved chemical compounds. 